\title{
Examen de una revista pedagógica-escolar (Argentina, inicios de siglo XX)
}

\author{
Inquiry of a pedagogical-school magazine \\ (Argentina, early twentieth century)
}

\begin{abstract}
Agustina Mosso ${ }^{1}$
Resumen

El presente escrito abre líneas de reflexión sobre maestras que utilizaron sus habilidades referentes a la lectoescritura, que la formación en el magisterio les brindó, para dar a conocer sus pensamientos pedagógicos en publicaciones educativas. Enmarcado en los estudios que implican hacer historia de la educación con/de mujeres bajo una perspectiva de género, el artículo se conforma en una fracción perteneciente a un conjunto de pesquisas que, en unidad, se vinculan al tema de investigación doctoral de la autora que gira en torno a maestras escritoras de sus prácticas didácticas y analiza una publicación perteneciente a la creación de una escuela normal, de Coronda, Santa Fe, Argentina, dirigida y organizada por educacionistas de inicios de 1900. El estudio pormenorizado de esta revista, a modo de tipo documental principal, permite determinar no solo el desempeño docente sino además el referente a la escritura de las prácticas educativas de un grupo de mujeres de la docencia argentina de principios de siglo XX.
\end{abstract}

\section{Palabras clave: maestras, escritura, revistas pedagógicas, normalismo}

\begin{abstract}
This paper reflects on teachers who used their literacy skills, which the teacher training provided, to show their pedagogical thoughts. Following the studies that involve making history with/of women from a gender perspective, the article belongs to a research whose research topic studies teacher writers of their practices. Thus, he analyzes a publication that belongs to the creation of a normal argentine school, of Coronda, Santa Fe, directed and organized by teachers.
\end{abstract}

Abstract

\section{Keywords: teachers, writing, pedagogical journals, normalism}

1ISHIR-CONICET. Correo electrónico: agustina_mosso@hotmail.com; mossoagustina@gmail.com 


\section{Introducción}

En respuesta a las investigaciones desarrolladas acerca de maestras argentinas productoras de saberes de principios de 1900, surge el presente escrito². Y en la búsqueda en bibliotecas y archivos pertenecientes a establecimientos educativos sobre material publicado por mujeres del magisterio de inicios de siglo XX es que mantenemos contacto con un profesor en lengua y literatura (Pablo Calgaro, quien se encontraba cumpliendo las funciones de bibliotecario), que cordialmente nos ofreció un compendio perteneciente a sus antepasados ${ }^{3}$. El vínculo lo entablamos en una visita realizada a la Escuela José Elías Galisteo, ex normal número uno de maestros, hoy Escuela de Enseñanza Media 201 de la ciudad de Coronda, Santa Fe, Argentina. El tipo documental que llega a nuestras manos, ya digitalizado, responde a ediciones de la revista Adelante!... Órgano de publicación de la Escuela Normal Mixta de Maestros Rurales de Coronda.

Bajo la metodología de investigación relativa al análisis de documentos históricos en perspectiva de género, y con una publicación de tipo escolar como fuente primaria a indagar, desentrañamos y damos a conocer (en acompañamiento de actas de fundación de la escuela y crónicas periodísticas que declaran su fecha inaugural los primeros días del mes de marzo de 1909), a continuación, ediciones de la revista de una escuela normal. Focalizaremos en el año 1912 (en que es más prolífica la presencia de sus tiradas), con el objeto de arribar a reflexiones relacionadas con los acontecimientos que dejaron entrever las posibilidades que el oficio docente brindó por fuera de la mera enseñanza en los salones de clase argentinos. Entonces, estudiaremos, por un lado, la publicación en sí y por otro, líneas biográficas sobre las mujeres a cargo de esta revista educativa para abordar y arribar a conclusiones sobre textos escolares escritos por educadoras argentinas.

\section{Qué leemos al interior de Adelante!..., cómo organizaron, las maestras, la revista}

Si observamos la edición del mes de marzo de 1912 distinguimos que la directora de Adelante!... era Carlota Garrido de la Peña (1870-1958). A ella la seguía María Margarita

\footnotetext{
${ }^{2}$ Escrito que forma parte del proceso de elaboración de la tesis titulada: "Maestras productoras de saberes. Prácticas de escritura, trabajo editorial y disputas intelectuales. Argentina 1880-1930". Para el Doctorado en Estudios de Género de la Universidad de Buenos Aires (Argentina), financiado por el Consejo Nacional de Investigaciones Científicas y Técnicas (CONICET- ISHIR- Rosario).

${ }^{3}$ Este artículo surge a partir de una ponencia presentada en las $V$ Jornadas de Investigación y Reflexión sobre Mujeres, Historia y Archivos a realizarse en la ciudad de Rosario, los días 17/18 septiembre de 2020. Con motivo de las medidas tomadas por la emergencia sanitaria, modificadas a modo de presentación de Actas de la Red Iberoamericana de Investigación en Historia, Mujeres y Archivos (RIIHMA).
} 
Gervassoni (1882-1940), ocupando el cargo en la secretaría pedagógica y administrativa. La institución (Escuela Normal) estaría dirigida por la última, Gervassoni, y su vicedirectora sería Elisa Alzugaray, profesora además de Instrucción Moral y Cívica. Al primer año de vida de la escuela habrían ingresado alrededor de treinta y dos alumnas, entre las cuales se encontraba Alfonsina Storni. Esta edición daría cuenta del cumpleaños número tres de la revista y de la escuela, creadas ambas en 1909 (las dos en el mes de marzo, a pesar de que algunos datos atestiguan que la primera publicación fue en 1910).

En el análisis cronológico de las ediciones de la Publicación de la Escuela Normal Mixta de Maestros Rurales de Coronda, observamos que las mismas se iniciaban generalmente con palabras a cargo de Garrido de la Peña o Gervassoni y en el transcurso de sus páginas se hacían presentes imágenes y fotografías alusivas a paisajes corondinos (con el nombre de Coronda Gráfico), comisiones de estudiantes, recepciones de maestros, reseñas sobre próceres y fechas patrias 5 . De acuerdo con Nicolás Arata (2014), la fijación de significados en torno a fechas específicas puede ser objeto de reflexión en la configuración de narrativas escolares sobre los llamados próceres, aunque también permite repensar rituales colectivos de la escuela pública; vinculados a la función socialmente transformadora del magisterio femenino en la prensa pedagógica argentina de inicios del siglo XX.

Extractos del Monitor de la Educación Común, órgano del Consejo Nacional de Educación dado a conocer con la Ley de Educación Común 1420 de 1884, también ocupaban secciones de la revista (tal el caso del título: Reflexiones de un maestro). Muy común también era la transcripción de discursos de veladas escolares, del por aquel entonces inspector de escuelas Eudocio Giménez como así también actas de fundaciones (de la Biblioteca Popular, del Club Unión Social). Con el correr de las tiradas notamos una nueva y mejor organización de los temas, que proponía tópicos para incluirlos. En la edición del 31 de octubre de 1912, por ejemplo, localizamos un apartado llamado "composiciones de los alumnos"; allí dentro leemos temas varios como la violeta, la salida del sol, un niño egoísta y la caridad. Un caso es el tema "la vanidad", en el que a modo de ejercicio de redacción participaban alumnos y alumnas de escuelas de Pueblo Borghi, Escalada, Villa Constitución y demás localidades de la amplia provincia de Santa Fe. Los estudiantes en ese apartado recitaban unas líneas.

En este apartado ("composiciones de los alumnos") leemos, por ejemplo, una llamada memoria de Alberdi, acerca de pensamientos de alumnas de sexto grado (Magdalena Andrada, María E. Alzugaray, Haydee Fernández, Rosa Berra). En otras ocasiones, más libres,

\footnotetext{
${ }^{4}$ La primera edición que poseemos tiene fecha 31/03/1912 (en el tercer aniversario de la escuela y también de la revista). Desde allí poseemos los ejemplares de las siguientes fechas: (30/04;31/05;30/06;31/07;31/08;30/07;31/10;15/12)

${ }^{5}$ El compendio compartido posee unas 216 páginas y se inicia con la edición número 18 del año III. Firma la tapa de puño y letra María Margarita Gervassoni. (Adelante!...Órgano de publicación de la escuela normal mixta de maestros rurales de Coronda. Marzo 31 de 1912). Gervassoni poseería vínculo familiar con quien nos facilita la fuente. La que obtenemos por dicha vía y no en un reservorio documental público.
} 
distinguimos el título "Sarmiento" (y allí escribía Alida Pérez, de $2^{\circ}$ grado) o "Mi escuela" (de Elisa Colautti de $3^{\circ}$ grado, de la Escuela Nacional de Nelson). "Las flores" de Ricardo Ambrosi de $4^{\circ}$ grado de la Escuela Fiscal de Villa Constitución y "La tarde en La Pampa" de María Ambrosi también de $4^{\circ}$ grado de la misma escuela. Los formatos eran variados; se convocaba un tema, éste no se explicitaba, a veces los autores exponían curso y lugar y otras tan solo su nombre ${ }^{6}$. También distinguimos escritos de estudiantes de la escuela corondina desde la que se editaba la revista (de $3^{\circ}$ y $4^{\circ}$ grado). Por ejemplo, la alumna de la escuela de San Carlos Centro (María N. Faure), en su fragmento "Lo que más quiero y por qué" decía: "La jescuela! En ese templo es donde se aprende a amar a la familia, a nuestros semejantes, a la Patria. Allí nos instruyen, nos inculcan sentimientos de patriotismo, nos enseñan a ser honrados, buenos, cultos y obedientes" (1913: 407).

Otras composiciones sobre la sombra de los árboles, el sauce y los libros dan cuenta de un amplio público escritor convocado por la revista. "Sueltos varios" será el apartado que enumerará donativos, agradecimientos a los colaboradores de la revista; quienes mediante pensamiento y acción hacían posible la divulgación del periódico. También allí leemos: un poquito de propaganda, canalización del río Coronda, exámenes, crónicas de las fiestas mayas. Además: visita al hospital, el auxiliar del maestro y laureles, donde se comenta sobre agradecimientos a obsequios, surgimientos de nuevas revistas, colectas voluntarias, conmemoraciones. Fragmentos con diálogos se incluían en una sección denominada "amena", donde había aparte de cuentos; relatos y fábulas.

Un caso es el texto "Vida Santafesina", de Luis Borruat, que se fracciona en dos partes y ambas aparecen por separado en reproducciones consecutivas de la revista Adelante!...

Nuevas secciones aparecían con el transcurso de las ediciones; tal el caso de la histórica (con títulos como damas patrióticas y anécdotas de próceres), la descriptiva (que presentaba en su interior narraciones sobre plantas, animales, regiones geográficas).

También identificamos la sección pedagógica (con planes de materias, variedades de lecturas, programas de clases públicas) y, en casos eventuales, el apartado de economía doméstica. Éste traería a colación recetas útiles, medicinas fáciles de preparar, perfumería doméstica. Otra unidad presentaría la propuesta de juegos mentales y escolares; allí encontramos las recreaciones denominadas "la cigüeña y las ranas", "la caza del ciervo" (juego que tenía por base el asalto), en las que se demostraba el procedimiento para llevar a cabo un entretenimiento, los objetivos, las características, las destrezas físicas implicadas en cada actividad, entre otras indicaciones. Ubicamos entonces un orden que va haciéndose más

\footnotetext{
${ }^{6}$ En otras composiciones de los alumnos leemos sobre efemérides como el nueve de julio (escritas por Margarita Arri, Teresa Carratini, Ramón y Augusto Questa). Como decíamos, en algunos casos los temas eran libres y convocaban títulos como un mandato de mamá, cuando yo sea maestro.

Mi muñeca, de Adela Pellanda y nuestra bandera de Juana Mulnetti; ambas de $3^{\circ}$ grado, de Gálvez (localidad cercana a Coronda). El invierno, de Ina Mangiaterra y las malas acciones de María Borda, eran escritos de alumnas de $4^{\circ}$ grado.
} 
metódico y minucioso con los años de publicación de la revista. Este boletín nace y acompaña lo acontecido dentro de la escuela y en sus primeros escritos (generalmente monólogo mediante) su mirada histórica daba a conocer la vida de San Martín, el himno nacional argentino (tal como lo escribió López), argentinos ilustres: Rivadavia y Sarmiento, la bandera de la patria: su conmemoración centenaria ( página eterna de argentina gloria...), (1812-9/3-1912) cien años en que las brisas del Plata acariciaron la frente de San Martín al desembarcar de la fragata inglesa en la ciudad de Buenos Aires, entre otros temas más.

Era habitual observar escritos referentes a aniversarios, cumpleaños, conmemoraciones y festejos acompañados muchas veces por fragmentos donde el inspector Giménez felicitaba a la escuela por sus honrosos modos con los que la institución se asociaba a los días patrios, y daba cuenta del reconocimiento de la normal expresado a través de la revista. En los últimos y primeros meses del año, cuantiosos datos sobre colaciones y egresos de la institución llenaban las páginas de Adelante!... Allí vimos los saludos de educadores que en dicha alocución justificaban su ausencia a los eventos (tal el caso de los santafesinos/as Juan Arzeno, Julio A. Busaniche, Julia Torrá, Severa L. Mori-rosarina esta última). El reconocimiento se efectuaba tanto por este tipo de personalidades como así también por padres de estudiantes. Con fecha 6 de marzo de 1912 firma en San Javier y se dirige a Gervassoni el padre de Carlos y Manuel. Lo hace para agradecer los adelantos que sus hijos obtuvieron en la escuela, una vez egresados del cuarto grado.

Aquellos progresos permitieron el ingreso de ambos (examen de por medio) al Colegio Industrial de la capital, con buenas calificaciones. La revista comunicaba y al mismo tiempo promocionaba su labor educativa de excelencia, única en la provincia. La profusión de agradecimientos, avales, felicitaciones y reverencias a la escuela otorgaban un siempre justificado reconocimiento.

Por otra parte, vemos cómo a pesar del receso escolar la revista seguía editándose y presentando contenidos referentes a creaciones de escuelas en Coronda, solicitudes de becas para que puedan asistir a la normal (única en la jurisdicción subvencionada por el gobierno territorial), de gestión regional, alumnos de diversos departamentos (en sexto grado un escrito expresa que concurrían de Santa Fe, Cañada de Gómez, San Carlos, Gálvez, Cayastá, Arocena, Santa Clara). La sección científica, de idioma, de composición, de economía práctica; descripciones geográficas, anécdotas históricas, métodos de enseñanza y biografías de grandes hombres argentinos y extranjeros componían un ejemplar de la revista en el que leíamos el deseo sostenido por parte de sus rectoras de trascender la provincia acompañando la labor educativa de la normal. Del mismo modo, la exposición de disertaciones como el discurso pronunciado en la fiesta del árbol por el Sr. Teodosio Cárdenas, con fecha treinta y uno de agosto de 1912, y peroratas de elogios, agradecimientos, salutaciones demostraban los lazos entablados por la escuela con otras instituciones educativas, culturales, sociales. En 
la edición que remite al mes de diciembre de dicho año distinguimos el estrecho vínculo que unía la escuela normal rural y la revista que la acompañaba; allí situamos informes de la regencia sobre trabajos expuestos a fin de año, junto a disertaciones de pedagogos/as. Actos de colación de grados, recepciones de maestros presididas por el gobernador provincial y ministros de instrucción pública y gobierno, bailes, discursos de despedida de alumnos graduados componen un varieté de prédicas que la revista Adelante!... creía conveniente comunicar a sus colaboradores?

Cabe aclarar que si bien las revistas son estimadas clave para la historia de la educación como así también la propuesta editorial (Depaepe y Simon, 2014), la aquí consultada posee su especificidad. Nuestro acercamiento a la fuente fue un tanto particular y tuvo las dificultades que suele poseer el trabajo de archivo (de escuelas).

Estuvo mediado primero por el acreedor de la revista, quien nos la compartió para observarla. En segundo lugar, pudimos analizar sólo unas ediciones del año 1912 en el que se cumplía el tercer aniversario de la Escuela Normal Mixta de Maestros Rurales de Coronda. Esta particularidad condiciona el tratamiento y análisis de la fuente.

Con alrededor de cuarenta egresados en ese momento, la revista daba cuenta de una formación de maestros de excelencia, que imponía menores sacrificios que las Escuelas Nacionales de otras provincias y garantizaba flamantes graduados que se insertarían en las escuelas santafesinas. Una reputación honrosa mencionada por la Inspección de la Superioridad (la cual fiscalizaba la marcha de la institución), iba de la mano de un trabajo diario a cargo de maestras que hacían buena obra educacionista de labor metódica, y lo sistematizaban por escrito en la revista. Surgiendo al público de las escuelas de su seno y para constatar su progreso (edición del mes de marzo de 1913), la publicación dejó entre sus hojas las huellas de su labor.

Circulando por infinitas escuelas del país, llevaba a quienes trabajaban en las aulas (maestros/as y niños/as) el eco de la simpatía necesario para aquellos/as que servían a la causa grandiosa de la educación del pueblo. Sus nuevas sesiones inauguradas en 1913 seguían incluyendo los contenidos habituales, pero en formatos diferentes, con nuevos aportes para estudiantes de magisterio y maestros/as. A continuación, indagaremos sobre los planes, programas, apuntes e ideas escritas por las directoras de la publicación para comprender un poco más sobre su labor en esa revista escolar.

Los rastros dejados a la posteridad para el análisis historiográfico de este tipo de fuentes permiten afirmar que la búsqueda de las mismas es infinita si tenemos en cuenta que hay un

\footnotetext{
${ }^{7}$ En el apartado "sueltos varios", por ejemplo, localizamos decretos y nombramientos de la escuela con carácter de mixta e inspecciones radiadas organizadas según lo establecido por la inspección de escuelas y las inspecciones seccionales. En "laureles" se comenta sobre agradecimientos a obsequios, surgimientos de nuevas revistas, colectas voluntarias, conmemoraciones, entre otros temas más.
} 
extenso campo con material afín por fuera de los marcos institucionales de los reservorios documentales. Visibilizar, situar, dar nombre a las mujeres en los archivos es un camino abierto (De Paz Trueba, Caldo, Vasallo, 2016: 6). Transitarlo en los bordes puede convocarnos a descubrir una riqueza de fuentes (libros, revistas, fotografías) tan valiosa como la presente en los archivos ${ }^{8}$.

\section{Gervassoni y Garrido de la Peña: maestras, lectoras y escritoras}

Como hacíamos mención en el apartado anterior, al crearse la Escuela Normal Rural, en el año 1909, algunas de las personalidades a cargo de la institución al momento de su fundación eran "María Gervassoni en la dirección y María Alzugaray en la vice dirección; Carlos Berra y Zenón Ramírez como regentes; Carlota Garrido de la Peña secretaria, habilitada y bibliotecaria; Emilia Pérez de Berra catedrática y Alfonsina Storni alumna celadora" (Sodero de Benedetti, 1984: 26). Como decíamos, Garrido de la Peña dirigió la revista: Adelante!... y cumplió además funciones en la Biblioteca Popular y otros espacios de la cultura corondina. "Garrido de la Peña (Mendoza, 02-08-1870/Coronda 19-07-1958) fue educadora, poetisa escritora de exquisita sensibilidad. Hija del distinguido y abnegado médico Mauricio Garrido, se estableció en Coronda en 1882" (Sodero de Benedetti, 1984: 33) Por su parte, la directora de la escuela, Gervassoni, en los inicios de la revista sería la secretaria administrativa de la misma. Quien se habría encargado además de dar a: Adelante!... nimios tratados de pedagogía, materia que dictaba en la escuela. También discursos y otros manuscritos dirigidos al magisterio, cuentos y relatos que en simultáneo publicaría en revistas de las ciudades de Santa Fe, Rosario, Rafaela. Propulsora de debates sobre cuestiones educativas, vinculadas a la enseñanza de la infancia, fue considerada por muchos "periodista", del mismo modo en que se la describía a Garrido de la Peña.

Margarita Gervassoni (Coronda, 03-02-1882/08-03-1940) era graduada de maestra normal de la vecina ciudad de Esperanza. Socia fundadora de la biblioteca popular" "Coronel

\footnotetext{
${ }^{8}$ Como decíamos antes, consultar Adelante!... nos eximió de suponer criterios de conservación, resguardo y acceso a la fuente porque lo hicimos por fuera de los centros documentales institucionalizados. Pero nos llevó a lidiar con otros modos de efectuar la consulta, de trabajar. Estos condicionamientos que exceden al trabajo propio al interior de un archivo a veces facilitan y otras dificultan la tarea de investigar e invitan a bregar para que esos materiales recorran los espacios públicos, sean fuentes de acceso abierto que incluyan a las mujeres en los repositorios documentales. De ahí nuestra participación en las V Jornadas de Investigación y Reflexión sobre Mujeres, Historia y Archivos (Rosario), para debatir sobre la problemática.

${ }^{9}$ En la edición con fecha 31 de octubre de 1912 de la revista leemos una reseña sobre la creación de la Biblioteca Popular de Coronda, cuya comisión (lo detalla el acta de fundación adjunta) está conformada por el presidente Eudocio S. Giménez (por entonces inspector de escuelas de la séptima sección), vice primero la señorita María M. Gervassoni, vice segundo el señor Vicente Cucurrullo, secretario el señor Waldo Bergallo, tesorera la señora Carlota Sandoz de Bonazzola, pro id. Señor Jorge Yunis. Vocales: doctor Luis Pizzariello, señores Santos Maciel y Pedro P. Giménez. También estaría Garrido de la Peña.
} 
José Rodríguez" junto a la directora de Adelante!... Ella también habría ocupado "la presidencia del Consejo Escolar de Distrito (durante el gobierno demócrata progresista del gobernador Luciano Molinas)" (Sodero de Benedetti, 1984). En la observación de las ediciones de la revista descubrimos que ambas maestras oscilarían en los puestos de dirección y jefatura de la sección pedagógica y administrativa. A su vez, Adelante!... habría dado a conocer su primer número el 25 de mayo de 1910 y su directora Garrido de la Peña, unos años después, dejaría la conducción de la publicación.

Ella cedería ese espacio a Gervassoni, con el objeto de ocupar el puesto de administración en calidad de secretaria, y acompañaría así la iniciativa desde otros cargos de gestión.

Multiplicadas a inicios de 1900 "las revistas pedagógicas eran guías de enseñanza preparadas por pedagogos para los mismos docentes" (Depaepe y Simon, 2014: 30). Adelante!... aportó preceptos para la teoría y la práctica educativas, sugerencias, inquietudes, desafíos acerca del magisterio, y construcciones discusivas marcadas por las condiciones de posibilidad de la época con singularidades femeninas. (Nari, 1995; Caldo, 2016; Aguilar, 2014; Giard, 2006; Fernández Valencia, 2006; Barrancos, 2007). Allí distinguimos el modo en que la maestra y escritora Carlota Garrido de la Peña hacía extensivos sus pensamientos (innovadores y de avanzada) sobre educación. En relación a la condición docente, por ejemplo, ella afirmaba: "Necesitamos maestras que sepan cumplir con altura su misión civilizadora, madres que sean modelos vivos en su hogar, mujeres ejemplares, útiles a su familia, a su pueblo, a la sociedad y a la patria" (1912). Según Garrido de la Peña se acrecentaba el número, en el periodo, de maestras de la provincia de Santa Fe designadas profesoras con el objeto de ocupar el puesto de subinspectoras de escuelas públicas. Al respecto alegaba: "En un país donde la mujer lleva impreso en su carácter y mentalidad el rasgo emprendedor y valiente de la raza, donde abundan médicas y empiezan a vestir la toga y el birrete doctoral en las facultades de derecho" (1912) resulta necesario y justísimo elevar a la mujer educadora de su pueblo un título honroso como el de inspectoras. Ella señalaba el triunfo en esas funciones de Malvina Zerda (oriunda de Santa Fe capital) y Amelia Villarroel (rosarina). En palabras de Carlota ambas féminas demostraron capacidad, altura de miras, conciencia profesional en el desempeño de sus funciones técnicas, crecidamente en manos de mujeres.

No obstante, también ella utilizaba a la publicación como vía para hacer visibles sus producciones escritas. Esto ocurre por ejemplo con su libro "Corazón argentino". En varios números de la revista leemos fragmentos del texto y anuncios acerca de su venta en las librerías; tanto su primera como segunda edición (esta última encuadernada en tela y aumentada con nuevos capítulos y grabados, ofertada también para maestros que directamente podían solicitar la obra a su autora, en Coronda). Otra propaganda de Corazón argentino, libro de lectura para $3^{\circ}, 4^{\circ}$ y $5^{\circ}$ grado, dice venderse en librerías de las ciudades de Rosario y Córdoba, con sus respectivos nombres y direcciones. Libro ameno, moral y patriótico, 
poseía descuentos si era comprado a su autora directamente. En ediciones posteriores a las de la aparición de los anuncios, leemos juicios sobre el texto, dos de los cuales creemos oportuno mencionar para estudiar en profundidad. Antes de ello realizamos una salvedad; Garrido escribirá esta versión nacionalizada del libro del mismo nombre, cuyo autor turinés era el reconocido Edmundo de Amicis, en Coronda. Los años de escritura del texto serían aquellos en los que la maestra se encontraría trabajando en la escuela normal rural y dirigiendo la revista que utilizaría para promocionar su libro de lectura; texto publicado con dinero propio y puesto a circular en escuelas y librerías por ella misma. Evidenciamos (con los extractos de la publicación mencionados en Adelante!...) a la maestra en pleno auge de su actividad escritural, acreditada por sus colegas en una tarea poco usual en las mujeres de inicios de siglo XX.

La primera reseña de "Corazón" está formalizada en Catamarca al día uno de julio de 1913. Es enviada a su autora por Margarita Todd de Tala. En Adelante!... ella agrega a la nota las siguientes palabras: "A una amiga de su distinción la maestra envía una reseña que será luego acompañada por la publicidad de este libro de lectura destinado a estudiantes de $4^{\circ}$ y $5^{\circ}$ grado..." Todd en aquel entonces se encontraba desarrollando una exitosa carrera dentro del magisterio tucumano y lograba expresar sus preocupaciones intelectuales y culturales circulando en espacios como la Sociedad Sarmiento (1882) y el Círculo del Magisterio (1905). Quizás su vínculo con Garrido de la Peña era el coincidir en habitar el espacio público que, por aquel entonces, conservaba una lógica fuertemente masculina. Este gesto comunicacional entre maestras asiste a las reflexiones sobre los lazos que Corazón entablaría, sus alcances. Otro juicio sobre la obra se encontrará en una edición posterior de la revista, esta vez realizado por el doctor José León Suárez, firmado el 25 de marzo de 1915. En el año 1917 Corazón de Garrido sería incluido en el listado de textos oficiales para utilizarse en las escuelas, por lo que estos mensajes previos quizás abonarían a que ese hecho se materialice. Retornando la comunicación con Todd, podemos imaginar que, en el marco del proceso de expansión de experiencias asociativas en la Tucumán de principios del siglo XX; ya sea en la búsqueda por perfeccionar las herramientas obtenidas en su paso por las instituciones escolares, o persiguiendo mejorar su situación laboral, la maestra habría traspasado los ambientes ajustados al aula para insertarse en tramas de sociabilidad educativa y cultural, al igual que Garrido de la Peña. Con el cambio de siglo el mundo de sociabilidad cultural se abría a pretensiones de mujeres que querían incorporarse a las actividades de lecturas, charlas, conferencias, cursos para una educación superior (Vignoli, 2015). Con su libro Corazón, Garrido daría a conocer "un libro de lectura perteneciente al género novela pedagógica en el que se combina la diégesis narrativa con la introducción de distintos contenidos curriculares. El texto de Garrido de la Peña se construye, entonces, como una trama polifónica de voces narrativas..." (Sardi, 2008: 384). 
La relación entre las maestras que vemos en Adelante!... no es más que entre dos mujeres pretensiosas de exceder los límites estipulados para las mujeres del magisterio y hacer uso de la escritura para circular por otros espacios públicos de la cultura de época.

La formación unía a estas maestras y el libro era excusa para comunicarse además en un momento en que Garrido de la Peña distribuiría su texto con sus ahorros, mediante correo y telégrafo, hasta tanto el Consejo Nacional de Educación lo seleccionaría para el ingreso en las listas de los textos aprobados y la autora firmaría convenio con la editorial Cabaut para reeditar e intercambiar el compendio. Como dijimos, además de desempeñarse en la escuela ella participaba en la actividad periodística publicando artículos en "La Revista de Derecho", Historia y Letras y en la Revista del Consejo Nacional de Mujeres. Fundadora de la revista literaria "El pensamiento" en 1893 y "La Revista Argentina”, en 1902 (Sardi, 2008: 381). Carlota Garrido de la Peña aprecia Adelante!... como un espacio más de circulación de sus textos.

Adentrándonos en la otra directora de la revista, María Margarita Gervassoni, descubrimos que sus producciones escritas allí solían remitir a acontecimientos de la historia argentina, próceres, efemérides (con citas a Víctor Mercante, Carlos Guido Spano, V. Blasco Ibáñez, Bartolomé Mitre, etcétera) ${ }^{10}$. También ella coordinaría en muchos casos las secciones denominadas "clases prácticas". Allí leemos dos a cargo de la señorita Ernestina Lage, por ejemplo, en las que se proponía trabajar para la asignatura zoología con el tercer grado mixto (tema fundamental: división del reino animal en vertebrados e invertebrados y caracteres de los mamíferos, para ser desarrollado en '25 aproximados), sobre la estética de la matemática (procedimiento ameno y con belleza de los problemas, donde se recomienda al profesor ser discreto, claro, breve. No llevar el empeño hasta descubrir reglas y efectuar definiciones por procedimientos discutibles). También leemos dentro de la sección lecciones de cosas referentes a un curso de niñas de primer grado dirigidas por la maestra Josefa M. de Núñez, también a trabajarse en 25 minutos aproximados, con la temática del reloj para aprender la hora.

En 1882 aconteció en Buenos Aires el Congreso Pedagógico Sudamericano, al que asistieron personalidades argentinas y de países hermanos. "Los debates contribuyeron a afirmar el concepto de que la acción educativa constituye uno de los deberes primordiales de la sociedad, y del Estado" (Arena, 1962: 157-158). Dos años después el Congreso Nacional, bajo su influencia, sancionó la Ley de Educación Común 1420.

En los debates del ' 82 la mayoría de los miembros coincidían en el pensamiento pestalozziano, el que debía servir de faro orientador en la reforma de la educación. "El pensamiento pestalozziano -introducido a través de la didáctica de los educadores norteamericanosprevaleció en la escuela argentina" (Arena, 1962: 160). Fue un pensamiento del que Gervassoni

\footnotetext{
10 También examinamos reseñas sobre el General Belgrano; una de ellas escrita por las maestras Amelia Montani y Aída Gervassoni, de $6^{\circ}$. Los escritos oscilaban entre la enseñanza en las aulas y la labor docente.
} 
tenía nociones claras, algunas quizás obtenidas en su formación como maestra, otras de lecturas que realizaba en lo cotidiano, pero todas desplegadas y puestas a consideración en la revista.

Leíamos en las clases prácticas la recomendación de proceder paso a paso y acabadamente, y así pasar de lo conocido a lo desconocido, considerando a Pestalozzi un enamorado de aquello que Rousseau imaginaba en la condición del pueblo por influjo de las madres, "...aquel que tomó a lo serio escribir y predicar en sus obras sobre las maravillas que podrían resultar de una educación doméstica bien dirigida" Para la maestra esa era la única base para desarrollar el más perfecto plan de educación intelectual, moral y física. Muchos principios pestalozzianos propuestos en las clases transcriptas en la revista sugerían preguntas preliminares instructivas, ilustraciones, métodos y procedimientos, con desarrollos que solían iniciar desde preguntas del docente y continuar con respuestas de los y las estudiantes. El manual de Pestalozzi del que hacía uso Gervassoni hacía foco en la actividad "ley en la niñez", junto al cultivo del lenguaje.

Hasta aquí, dos maestras en vínculo con otras coterráneas o de provincias lejanas. "Pesquisar sus trayectorias, biografías, líneas de pensamiento, prácticas, y posicionamientos políticos se presenta como un accionar que no debe desatender la relación constante de dichas mujeres con sus colegas..." (Caldo y Vignoli, 2016: 54). Solo así es posible discutir en clave de género la semántica habitada detrás del sustantivo universal y frecuentemente utilizado por la historia de la educación "maestros". La revista deja ver las relaciones entabladas entre el propio colectivo femenino del magisterio; estudiantes, maestras, condiscípulas. Todas asumiendo una labor externa a la de enseñar en las aulas, pero vinculante; la lectura y escritura de las prácticas educativas. Ellas apuntaron sus ideas por escrito y esas destrezas las posicionaron en espacios distintos a los de la mera reproducción de saberes escolares, al mismo tiempo que las habilitaron a compartir e intercambiar con actores del ámbito de los espacios públicos, en los cuales no estaban acostumbradas a desempeñarse, inquietudes culturales, educativas, sociales. Encontrar estas experiencias en una revista pedagógica abre interrogantes que cuestionan los modos de permanecer en los espacios públicos de las mujeres, de vincularse, cumplir las normas establecidas por el sistema educativo, trabajar, vivir su condición docente.

\section{Conclusiones}

En el transcurso del escrito intentamos describir el trabajo efectuado por un grupo de maestras bajo una iniciativa particular; la edición de una revista que escoltaba su desempeño 
en una Escuela Normal Rural argentina. Nos centramos en una característica que consideramos interesante; el vínculo entre mujeres de la educación y escritura.

Dicha institución educativa armonizaba con el ideal de educación popular indivisible que las mujeres encargadas de llevar adelante la iniciativa defendían (Garrido de la Peña y Gervassoni, fundamentalmente). Para ellas la aspiración común honrada por la normal y la revista que la acompañaba, no reconocía fronteras ni territorios. Dirigida en pos de la educación pública como señal de progreso e intelectualidad nacional, esta dinámica escolar a cargo de mujeres reflexionaba sobre las cualidades de un buen educador, la mujer maestra. En "siluetas femeninas" lellamos; "La figura dignísima de maestra es adalid de nuestro adelanto futuro, nuestra civilización presente. Ella se dedica a encender la idea en el cerebro del niño que ávido, toma el pensamiento, la palabra y la acción de su modelo vivo" (Garrido de la Peña, 1914: 544). En ese texto Carlota Garrido de la Peña reconoce la labor de la educacionista argentina, quien coopera a llevar la luz del saber a las mentes de sus compatriotas de manera desinteresada, con constancia, responsabilidad y sin pretensiones y retribución similar a la de otras profesionales modernas. Ella desempeña su misión eminentemente civilizadora sin ser tomada en cuenta, ni galardonada en libros de oro. La autora afirmaba: "las jóvenes maestras argentinas van allí donde el maestro no quiere ir por ausentarse de los centros de población, a enterrar su juventud, ideales, belleza, en las regiones incultas de nuestras campañas" (Garrido de la Peña, 1914: 544). Según Garrido de la Peña ellas combatían el analfabetismo y estaban a cargo de "la tarea de descortezar almas y cerebros dormidos en el sopor de la ignorancia" (Garrido de la Peña, 1914: 544). La dupla Gervassoni-de la Peña se convirtió en un par de maestras capaces de levantar una modesta escuela, una prestigiosa revista, una humilde biblioteca. Ellas, al mismo tiempo, elevaron el plantel de la civilidad de las costumbres.

Considerándose colaboradoras con la civilización de la patria, ambas educacionistas defendieron una labor que debía recompensarse proporcionadamente de acuerdo a la importancia de su tarea, cómplice del adelanto social, de la ilustración de su intelectualidad. La que generaba, en aquellos lugares que escaseaba, el despertar en la mente de hijos e hijas del pueblo (los y las estudiantes) el tan valioso deseo de saber.

Para estas educadoras y escritoras su obra pedagógica era acción inteligente y abnegada a favor de la cultura argentina que impulsores, como Mercante -de cita recurrente en la revista de la escuela normal-, habían prefijado en su formación de maestras normales ${ }^{12}$.

\footnotetext{
${ }^{11}$ Carlota Garrido de la Peña (firmado en el mes de diciembre de 1913).

12 En "Impresiones de un extranjero sobre la escuela argentina", de V. Blasco Ibáñez leemos: "...lo que más interesa a extranjeros en la enseñanza de la república no es la escuela de niños. Hoy la escuela argentina creó una generación de mujeres aficionadas al libro, versadas en conocimientos que constituyen una ilustración general y muy mujeres sin la pedantería ni el aspecto hombruno de las que creen que para elevarse la mujer intelectualmente necesita abdicar de todos los encantos del sexo. En muchos hogares argentinos la mujer que ha pasado por la escuela normal tiene una visible superioridad sobre el marido, dedicado en absoluto a los negocios y olvidado de lo que aprendió en las aulas.
} 
Adelante!... formó parte de ese sinnúmero de revistas pedagógicas que proliferaron en el devenir de la primera mitad de siglo XX pero no se conservan en archivos y bibliotecas ${ }^{13}$. Fue una publicación que transitó por las aulas de la escuela y excedió los salones de clase para convocar, por ejemplo, bajo el apartado "Composiciones de los alumnos", a estudiantes y maestras/os a declarar sus pensamientos sobre algún prócer, acontecimiento histórico, suceso cultural. Poemas, poesías y pronunciaciones de variada índole se entreveraban en las páginas de una revista perteneciente a una institución educativa organizada y llevada adelante por mujeres. Estas maestras de Coronda, con la escuela y la revista, desarrollaron un proyecto educativo que trabajó, progresó y comunicó sus logros. Una composición de una alumna de la ciudad de Rafaela, con fecha 10 de octubre de 1913 y firmada por Blanca A. Soto, expresaba: "Adelante!... es una revista instructiva, un entretenimiento por sus páginas amenas. Sus dirigentes son la distinguida directora de la escuela y la secretaria. En ella se publican composiciones, lecturas históricas, anécdotas y cuentos. Su nombre parece que alentara a los estudiantes en su pesada labor". Es esta expresión señal de que Gervassoni y Garrido de la Peña poseían el reconocimiento social de quienes las apreciaban; tal el caso de la pequeña escritora de quinto grado, quien en su texto confirma nuestras sospechas: la revista recorría Coronda, su lugar de origen, se propagaba por muchas otras manos y dejaba gratas impresiones en sus abonados. Lo hacía gracias al contenido escrito proporcionado por sus directoras, para muchos de los lectores y las lectoras de la publicación victoriosas ambas en la lid del periodismo.

Para finalizar con el escrito mencionamos una aclaración sugerente que párrafos antes insinuamos; elegir una revista a modo de fuente documental, que nos brinda aspectos interesantes para el estudio de la labor desempeñada por un grupo de maestras argentinas de principios de siglo XX, implica considerar que si bien el magisterio fue un oficio de presencia femenina, sus fundamentos estuvieron labrados sobre la base de un universal genérico (masculino), que es "solo posible de deconstrucción si buscamos otras fuentes y si incorporamos la mirada local-regional que sitúa las prácticas y así permite reconocer la agencia de los varones, pero también de las mujeres" (Caldo, 2017: 58).

En este caso maestras que además de ejercer su labor docente leyeron, comentaron esos escritos, narraron los suyos y en dicho plano trabaron amistades con un sinnúmero de personalidades educativas y culturales del momento. Las secciones de las revistas observadas variaron con el transcurso del tiempo; intuimos éste fue un ejercicio escritural que dio el siguiente resultado: a mayor experiencia en la edición de la publicación mejores sistematiza-

La maestra argentina es mejor que la de otros países. Muchas cumplen su deber prestando actividad a la patria igual que hombres lo hacen en el servicio militar..." (Tomado de una edición de Adelante!... del año 1912).

${ }^{13}$ Podríamos abrir nuevas reflexiones aquí referentes al papel que cumplen las instituciones educativas en el resguardo de sus documentos escritos, el modo en que pueden aprovecharse las virtudes de las nuevas tecnologías para sistematizar material ajeno a los archivos y así ponerlos a circular, entre otros temas. 
ciones y ordenamientos de los contenidos didácticos. Como dijimos, en relación a la autoría de los artículos, advertimos los iniciales a cargo de las directoras de Adelante!... acompañados luego por comunicados de estudiantes y maestras de la Normal Rural como así también autoridades educativas provinciales, otros/as pedagogos/as. A pesar de que en la época el reparto de la producción de saberes convocaba primero a los varones y la ciencia estaba en sus manos, esta revista vino a representar un conjunto de voces femeninas a cargo de aspiraciones educativas que les pertenecían; las maestras dirigieron una escuela, una revista y dieron a conocer producciones escritas de saberes que desarrollaban a diario, de ahí quizás el formato versátil de la publicación.

El presente estudio de la revista, por cierto, escueto, nos permitió dilucidar exámenes pendientes, pero dejar en claro otros; hasta aquí y a través de una mirada generalizada pudimos conocer el estado de situación de la escuela como así también el de sus maestras y maestros, estudiantes, egresados y graduadas.

Asimismo, advertimos características fundantes de la educación corondina, de la mirada (femenina) efectuada por las regentes de la Normal hacia el resto de las instituciones educativas, sus postulados generales sobre la instrucción argentina de inicios de 1900. Bajo el universo escolar en el que se enmarcaba Adelante!... distinguimos el modo en que la revista pudo utilizarse en calidad de herramienta para estas educadoras deseosas de repensar, cuestionar, analizar e informar los juicios que en simultáneo a su ejercicio docente realizaban y expresarlos por escrito, rebasando la tarea primera para la que habían sido formadas: educar al ciudadano. 


\section{Archivos consultados}

Biblioteca de la Escuela de Enseñanza Media N²01 "Elías Galisteo" (San Martín 1152) Coronda, Santa Fe. Contacto desde allí entablado con el arriba referido profesor en lengua y literatura, Pablo Calgaro, quien nos permitió la consulta a la revista (de su propiedad).

\section{Referencias hemerográficas}

Adelante!...Órgano de publicación de la escuela normal mixta de maestros rurales de Coronda. Coronda, Santa Fe. Ediciones con fecha: 31/03 (núm. 18 año III); 30/04; 31/05; 30/06; 31/07; 31/08; 30/07; 31/10; 15/12 del año 1912 (216 páginas).

Caldo, Paula y Marcela Vignoli (Coords.) (2016), "Dossier I. Mujeres en la historia de la educación. Maestras, prácticas, género e historia: hacia una historia de la educación en los tiempos de la consolidación de los sistemas educativos" en Anuario de Historia de la Educación. Vol. 17. Núm. 2. pp. 53-56.

Vignoli, Marcela (2011), "Educadoras, lectoras y socias. La irrupción de las mujeres en un espacio de sociabilidad masculino. La Sociedad Sarmiento de Tucumán (Argentina) entre 1882 y 1902" en Secuencia. Revista de historia y ciencias sociales, Instituto José María Luis Mora Mora, México. - (2015), "Trayectoria educativa y prácticas asociativas de una tucumana de entre siglos: Margarita Todd, maestra normal" en Historia y Memoria, núm. 11. pp 123-149.

\section{Referencias bibliográficas}

Arata, Nicolás (2014), Efemérides. Una oportunidad para pensar la vida en común, Estación Mandioca, Buenos Aires.

Arena, Luis (1962), Historia de la educación. Cuarto año del magisterio. Periodo contemporáneo, Ángel Estrada y Cía, Buenos Aires.

Bandieri, Susana y Sandra Fernández (Coords.) (2017), La historia argentina en perspectiva local y regional. Nuevas miradas para viejos problemas, Teseo, Buenos Aires.

Depaepe, Marc y Frank Simon (2014), "Qui ascendit cum labore, descendit cum honore. Sobre el trabajo con las fuentes: consideraciones desde el taller sobre historia de la educación”, en Federico Lanzarín Miranda, Luz Elena Galván Lafarga y Frank Simon, Poder, Fe y Pedagogía. Historias de maestras mexicanas y belgas, UAM, México.

Maristany, José (2001), Un libro para "el corazón de los ciudadanos y las madres del porvenir: Corazón argentino de Carlota Garrido de la Peña" en María Celia Vázquez y Sergio Pastormerlo (Comp.), Literatura argentina. Perspectivas de fin de siglo, Eudeba, Buenos Aires.

Sardi, Valeria (2008), El rol de la literatura en la escuela primaria argentina en el marco de la constitución de identidades nacionales (1900-1940), Tesis de posgrado. Universidad Nacional de La Plata. Facultad de Humanidades y Ciencias de la Educación, Buenos Aires.

Sodero de Benedetti, María Ernestina (1984), La primera escuela normal de la provincia de Santa Fe "Escuela Normal Mixta de Maestros Rurales de Coronda", Artegraf, Coronda.

Vasallo, Jaqueline, Yolanda de Paz Trueba y Paula Caldo (Coords.) (2016), Género y documentación: relecturas sobre fuentes y archivos, Instituto de Geografía, Historia y Ciencias Sociales, Córdoba. 